\title{
Left ventricular performance in children: transthoracic versus transoesophageal measurement of $M$ mode derived indices
}

\author{
Tamara C Martins, Michael L Rigby, Andrew N Redington
}

\begin{abstract}
Objective-To compare $M$ mode derived indices of left ventricular performance obtained with transthoracic and transoesophageal echocardiography in children with congenital heart disease.

Design-Transthoracic and transoesophageal $M$ mode echocardiograms were obtained under general anaesthesia before cardiac catheterisation. Recordings were digitised by dedicated software. Indices of cavity dimension and left ventricular wall dynamics were compared.

Patients-16 unselected patients with congenital heart disease.

Results-Group data for simple measurements of ventricular dimension and wall thickness were similar with the two techniques and had acceptable coefficients of repeatability, but there were considerable individual differences. Correlation was poor with unacceptable repeatability for derived indices of cavity and ventricular wall dynamics.

Conclusion-Both transthoracic and transoesophageal echocardiography can be used to obtain $M$ mode derived indices of left ventricular performance but the resultant measurements are not directly comparable, presumably because of regional non-uniformity of function.
\end{abstract}

\section{(Br Heart J 1992;87:485-7)}

With increasing availability and reduction in size of transoesophageal echocardiographic equipment transoesophageal echocardiography is rapidly becoming the imaging technique of choice in children in operating theatres, intensive care units, and during interventional cardiac catheterisation. The accurate assessment of ventricular performance is clearly important in all of these areas.

Until now the assessment of left ventricular performance with $M$ mode echocardiography has largely been restricted to recordings obtained through the transthoracic window. It should be possible, however, to obtain potentially comparable information during transoesophageal echocardiography and the purpose of this study was to compare indices of left ventricular performance obtained from children with congenital heart disease undergoing simultaneous transthoracic and transoesophageal echocardiography.

\section{Patients and methods}

Twenty two unselected children with congenital heart disease were studied. All were undergoing cardiac catheterisation with general anaesthesia as part of their preoperative assessment. The transthoracic $M$ mode recordings were unsatisfactory in six patients leaving 16 in whom comparative data were available. The ages of these patients ranged from three months to 17 years (median five years and four months) and their weight ranged from $4.9-55.4 \mathrm{~kg}$ (median $19 \mathrm{~kg}$ ). Table 1 gives the full sequential diagnosis for each of the 16 patients.

The procedure was identical in all patients. After endotracheal intubation a transoesophageal probe was inserted. In children over $12 \mathrm{~kg}$ a standard adult sized $5 \mathrm{mHz}$ single plane phased array transducer was used. In three patients a developmental paediatric probe was used. This had a shaft diameter of $6 \mathrm{~mm}$ and a switchable $7.5-5 \mathrm{mHz}$ single plane phased array transducer mounted at its tip. Both probes were interfaced with a Hewlett-Packard sonus 1000 ultrasound system.

A transoesophageal gastric short axis view of the left ventricle was taken from each patient. Left ventricular $M$ mode recordings were taken across its maximal dimension at the level of the mitral valve tips. As soon as possible after this, with the transoesophageal probe in place, a transthoracic recording of the left ventricular $M$ mode, again at the level of the mitral valve leaflet tips, was obtained in either parasternal short axis or long axis sections. Care was taken to maintain all haemodynamic variables unchanged throughout

\section{Table 1 Diagnoses of individual patients}

\begin{tabular}{|c|c|}
\hline Patient & Diagnosis \\
\hline 1 & $\begin{array}{l}\text { Pulmonary atresia with ventricular septal defect. } \\
\text { Previous Blalock-Taussig shunt }\end{array}$ \\
\hline 2 & $\begin{array}{l}\text { Previous repair of total anomalous pulmonary } \\
\text { venous drainage }\end{array}$ \\
\hline 3 & Valvar aortic stenosis \\
\hline 4 & Umbrella closure of ventricular septal defect \\
\hline 5 & Umbrella closure of arterial duct \\
\hline 6 & Umbrella closure of arterial duct \\
\hline 7 & Ventricular septal defect, pulmonary hypertension \\
\hline 8 & Supravalvar aortic stenosis, pulmonary stenosis \\
\hline 9 & Previous repair of tetralogy of Fallot \\
\hline 10 & Supravalve mitral membrane, subaortic stenosis \\
\hline 11 & $\begin{array}{l}\text { Double inlet left ventricle, discordant } \\
\text { ventriculoarterial connexion, previous Fontan } \\
\text { procedure }\end{array}$ \\
\hline 12 & $\begin{array}{l}\text { Ventricular septal defect, subaortic stenosis, mitral } \\
\text { stenosis }\end{array}$ \\
\hline 13 & Umbrella closure of arterial duct \\
\hline 14 & Tunnel subaortic stenosis \\
\hline 15 & Balloon dilatation of coarctation of aorta \\
\hline & Umbrella closure of arterial duc \\
\hline
\end{tabular}


Table 2 Group data (mean (SD)) for each of the indices with each technique

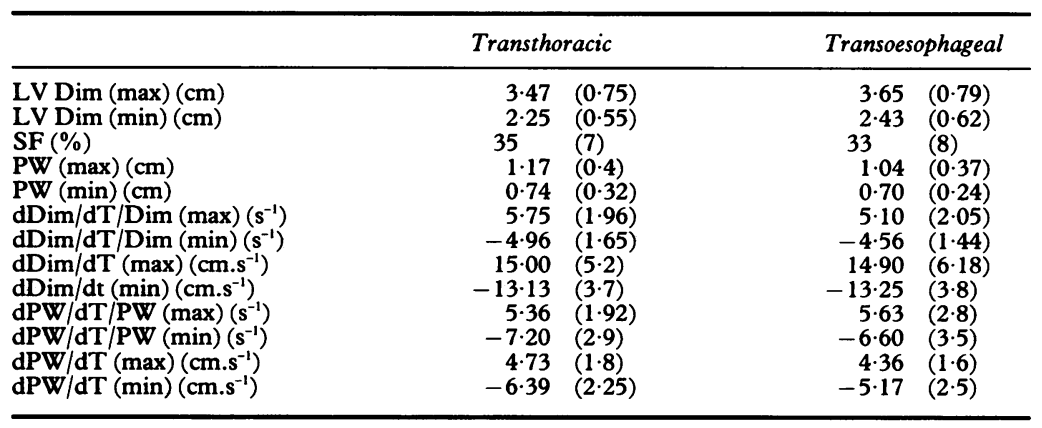

LV Dim, left ventricular dimension; SF, shortening fraction; PW, posterior wall.

both recordings. A simultaneous electrocardiogram, and where possible a phonocardiogram, was recorded in each patient. All recordings were made at a paper speed of $100 \mathrm{~mm} / \mathrm{s}$.

\section{DATA ANALYSIS}

The $M$ mode recordings were measured with a system previously described in detail. ${ }^{1}$ Data points were taken at $10 \mathrm{~ms}$ intervals throughout the cardiac cycle. For each of the indices measured the mean of three consecutive beats was taken. The measurements made were: maximum left ventricular dimension $(\mathrm{cm})$; minimum left ventricular dimension $(\mathrm{cm})$; rate of change of ventricular dimension $\left(\mathrm{cm} . \mathrm{s}^{-1}\right)$; standard rate of change of dimension $\left(\mathrm{cm}^{-1}\right)$; maximum posterior wall thickness (cm); minimum posterior wall thickness $(\mathrm{cm})$; rate of change of posterior wall thickness $\left(\mathrm{cm} . \mathrm{s}^{-1}\right)$; standardised rate of change of posterior wall thickness $\left(\mathrm{s}^{-1}\right)$; shortening fraction (\%).

\section{STATISTICAL ANALYSIS}

All group data were expressed as mean (1 SD). Comparison of the two techniques was by linear correlation with the method of least squares, and by the coefficient of repeatability with the method of Bland and Altman. ${ }^{2}$

\section{Results}

Table 2 shows the group data for each of the indices, with each method. Table 3 shows the correlation coefficient between variables from each technique and the coefficient of repeatability for each index of left ventricular function.

Table 3 Comparison of methods

\begin{tabular}{|c|c|c|c|}
\hline & $\begin{array}{l}\text { Correlation } \\
\text { coefficient }\end{array}$ & p Value & $\begin{array}{l}\text { Coefficient of } \\
\text { reproducability }\end{array}$ \\
\hline LV Dim $(\max )(\mathrm{cm})$ & 0.919 & $<0.01$ & 0.62 \\
\hline LV Dim (min) (cm) & 0.911 & $<0.01$ & 0.52 \\
\hline SF $(\%)$ & 0.78 & $<0.01$ & $9 \cdot 8 \%$ \\
\hline$P W(\max )(\mathrm{cm})$ & 0.885 & $<0.01$ & 0.38 \\
\hline$P W(\min )(\mathrm{cm})$ & 0.852 & $<0.01$ & 0.34 \\
\hline $\mathrm{dDim} / \mathrm{dT} / \mathrm{Dim}(\max )\left(\mathrm{s}^{-1}\right)$ & 0.699 & $<0.01$ & $3 \cdot 1$ \\
\hline $\mathrm{dDim} / \mathrm{dT} / \mathrm{Dim}(\min )\left(\mathbf{s}^{-1}\right)$ & 0.83 & $<0.01$ & 1.8 \\
\hline $\mathrm{dDim} / \mathrm{dT}(\max )\left(\mathrm{cm}^{-1} \mathrm{~s}^{-1}\right)$ & 0.53 & $<0.05$ & $11 \cdot 2$ \\
\hline $\mathrm{dDim} / \mathrm{dt}(\mathrm{min})\left(\mathrm{cm} \cdot \mathrm{s}^{-1}\right)$ & 0.73 & $<0.01$ & $5 \cdot 5$ \\
\hline $\mathrm{dPW} / \mathrm{dT} / \mathrm{PW}(\max )\left(\mathrm{s}^{-1}\right)$ & 0.028 & NS & $7 \cdot 9$ \\
\hline $\mathrm{dPW} / \mathrm{dT} / \mathrm{PW}(\min )\left(\mathrm{s}^{-1}\right)$ & 0.006 & NS & $9 \cdot 9$ \\
\hline $\mathrm{dPW} / \mathrm{dT}(\max )\left(\mathrm{cm}^{\left.-\mathrm{s}^{-1}\right)}\right.$ & 0.55 & $<0.05$ & $3 \cdot 2$ \\
\hline $\mathrm{dPW} / \mathrm{dT}(\mathrm{min})\left(\mathrm{cm} \cdot \mathrm{s}^{-1}\right)$ & 0.57 & $<0.05$ & $4 \cdot 4$ \\
\hline
\end{tabular}

See footnotes to table 2 for abbreviations.

\section{Discussion}

This study is the first to compare transthoracic and transoesophageal $M$ mode indices of left ventricular performance in children with congenital heart disease. In general, reasonable agreement was found between the two techniques when comparing left ventricular dimensions. In particular, agreement between the two techniques for left ventricular maximum dimension, minimum dimension, and shortening fraction was good, with correlation coefficients of $0.8(p<0.01)$ or more and with acceptable coefficients of repeatability. Similar results have been found in adults with acquired heart disease. Comparisons of transoesophageal echo with epicardial ${ }^{3}$ and transthoracic ${ }^{4}$ echocardiography generally show good agreement for ventricular dimension between the two techniques. Agreement was poorer, but still acceptable, for rates of change of ventricular dimension in our patients. We also compared left ventricular wall dynamics. Whereas the two techniques showed good agreement in terms of absolute wall thickness, both maximum and minimum, there was little or no agreement between the techniques when the rate of change of wall thickening and thinning was examined. Indeed, the poor coefficient of repeatability precludes direct comparison of indices obtained with the two techniques. Furthermore, whereas there was reasonable agreement when the indices were compared, considerable variability occurred on an individual basis. Thus, although a correlation coefficient of 0.9 and an excellent coefficient of repeatability was found when comparing left ventricular maximum dimension, individual differences of over $0.5 \mathrm{~cm}$ were seen. This is not surprising; regional non-uniformity of ventricular dimension and function is present in the normal heart and we have shown previously that the additional structural abnormalities imposed by congenital heart abnormalities and surgery will often result in abnormalities of regional wall motion. ${ }^{56}$ This presumably also accounts for the noticeable differences in ventricular wall dynamics. Here measurements are not only subject to this acquired regional non-uniformity but also will be related to anatomical differences in the area of myocardium being examined. Whereas the left ventricular posterior wall examined from a parasternal short axis view is a true posterior structure, posterior and caudal to the insertion of the posterior mitral papillary muscle, the comparable part of the ventricle recorded on the $M$ mode echocardiogram from a gastric short axis view is more anterolateral and closer to the interventricular septum. The case for the anterior wall of the left ventricular cavity is the same. In the parasternal short or long axis section the anterior wall of the ventricular cavity is the posterior surface of the interventricular septum, whereas in the gastric short axis view it will be the more posteromedial part of the left ventricular free wall. Thus, in general, it is not possible to compare directly group or individual data from the two techniques. Our patients, however, represent a 
heterogeneous group. It is possible that data from a more homogeneous group would compare more favourably. Furthermore, we did not examine the reproducibility of repeated measurements from the transoesophageal approach, but it is likely that repeated measurements from either technique will provide valid data for the sequential assessment of left ventricular performance.

In summary, transoesophageal echocardiography can provide useful information about left ventricular performance. Data obtained from this technique cannot be directly compared with data obtained from transthoracic echocardiography as both group and individual variability is unpredictable.
We thank Dr D Gibson for making the digitising equipment available to us and Ms J Peatling for typing the paper.

1 Gibson DG, Brown DT. Measurement of instantaneous left ventricular dimension and filling rate in man, using echocardiography. Br Heart J 1973;35:1141-9.

2 Bland JM, Altman DG. Statistical methods for assessing agreement between two methods. Lancet 1986;1:307-12.

3 Konstadt SN, Thys D, Mindich BP, Kaplan JA, Goldman M. Anesthesiology 1986;65:418-21.

4 Matsumoto M, Oka Y, Strom J, et al. Application of transoesophageal echocardiography to continuous intraoperative monitoring of left performance. $A m J$ intraoperative monitorin
Cardiol 1980;46:95-105.

5 Lincoln C, Redington AN, Li K, Mattos S, Shinebourne EA, Rigby ML. Anatomical correction for complete transposition and double outlet right ventricle: intermediate assessment of functional results. Br Heart $J$ 1988;59:23-30.

6 Penny D, Redington AN. Angiographic demonstration of incoordinate motion of the ventricular wall after the Fontan operation. Br Heart J 1991;66:456-9. 